\title{
Hidden waiting times of elective surgery
}

\author{
Owen Matthew Bradfield
}

Received: 11 August 2008 / Accepted: 15 August 2008 /Published online: 3 September 2008

(C) Springer Science + Business Media, LLC 2008

To the editor,

Performance measurement is now an essential part of health services management, with a proliferation of performance indicators over the last 10 years. As a result, evidence must continue to guide and inform their ongoing use [1]. Long waiting times are frequently portrayed by the media and governments as indicators of poor health system performance. However, given that waiting lists are primarily created to support internal management and clinical decision making, care should be exercised when using them as indicators of performance [2].

With this in mind, Brasted should be congratulated on his novel and elegant paper "Ultrasound waiting lists: queue or extended capacity?"[3], as it represents a valuable contribution to the current literature on waiting lists and performance measurement. Diagnostic imaging, like elective surgery, is a limited resource, with demand usually exceeding supply. However, as Brasted points out, the literature on waiting times for diagnostic imaging is limited compared to that for elective surgery.

A fundamental limitation with many elective surgical waiting lists is that they fail to disclose the 'hidden' waits prior to elective surgery. For instance, before being added to a waiting list, patients must wait to see a general practitioner for a referral, and then must wait for an appointment with a surgeon before waiting to access pathology and radiology services. To date, little is known about the relationship between waiting times for diagnostic imaging and waiting times for elective surgery. Therefore, Brasted's attempts to characterize and model the supply and demand of diagnostic imaging services will greatly assist in the planning and management of both diagnostic imaging services and elective surgery.

Ultimately though, waiting lists cannot expose definitive truths about the quality or safety of health services because that is not their primary purpose. Instead, they are tools to prompt and guide additional inquiry and investigation. This is true of surgical waiting lists as it is of waiting lists for ultrasound. This must be recognised by politicians, patients, health professionals and policymakers [4]. In this regard, Brasted's paper is seminal.

\section{References}

1. Davies HT, Lampel J (1998) Trust in performance indicators. Qual Health Care 7:159-162

2. Cromwell DA, Griffiths DA (2002) Waiting time information services: how well do different statistics forecast a patient's wait. Aust Health Rev 25(6):75-85

3. Brasted C (2008) Ultrasound waiting lists: rational queue or extended capacity. Health Care Manage Sci 11:196-207 doi:10. 1007/s10729-008-9064-9

4. Stoop AP, Vrangbæk K, Berg M (2005) Theory and practice of waiting time data as a performance indicator in health care: a case study from The Netherlands. Health Policy 73:41-51 doi:10.1016/j. healthpol.2004.10.002
O. M. Bradfield $(\bowtie)$

Monash University,

P.O. Box 2085, Preston, Victoria 3072, Australia

e-mail: owenbrad@yahoo.com.au 